\title{
Willingness of Bachelor of Pharmacy (B.Pharm.) students to be custodians of Complementary and Alternative Medicine (CAM): case study of Kenyatta University, Nairobi
}

\author{
Ikoni OGAJI ${ }^{1,2 *}$, Jackson LUBAYO ${ }^{1}$ and Fullaila O. ALIYU ${ }^{3}$ \\ ${ }^{I}$ Department of Pharmacy and Complementary and Alternative Medicine, School of Medicine [Now School of \\ Pharmacy], Kenyatta University, P.O. Box 43844-00100, Nairobi. Kenya. $\quad{ }^{2}$ Department of Pharmaceutics and \\ Pharmaceutical Technology, Faculty of Pharmaceutical Sciences, University of Jos, PMB 2084-930001, Jos. \\ Nigeria. [Current Address]. $\quad{ }^{3}$ Department of Clinical Pharmacy and Pharmacy Practice, Faculty of \\ Pharmaceutical Sciences, University of Ilorin, PMB 1515, Ilorin. Nigeria
}

Received $5^{\text {th }}$ June 2020; Accepted $9^{\text {th }}$ September 2020

\begin{abstract}
Appropriate training on standardization of quality characteristics of complementary and alternative medicine (CAM) practices has the potential to pave way for integrative and collaborative healthcare delivery in African health facilities. The purpose of this study was to understand how willing pharmacy students are to taking on the custody of CAM, especially provision of expertise services on traditional medicines. A questionnaire on the willingness of Bachelor of Pharmacy students to be trained and certified as CAM experts in an integrated health system was administered to one hundred and nineteen (119) pharmacy students of Kenyatta University, Nairobi, Kenya. Ninety-four respondents (78.99 \%) were excited to be trained on CAM and become experts on CAM alongside orthodox but not solely on CAM. Majority of the respondents acknowledged the important role of CAM in the nation's healthcare delivery system but were not ready to be trained solely as such without the commitments of governments for better status. The study revealed that with necessary support from governments and stakeholders, specialists from those desiring to study pharmacy can be developed to focus on safety, purity and efficacy of CAM, especially traditional medicines, to enhance their incorporation into the national healthcare system.
\end{abstract}

Keywords: Pharmacy students; CAM; Experts; Integrative healthcare system

\section{INTRODUCTION}

The greater accessibility, cultural acceptance and the comparatively low cost of herbal medicine make its use very popular in Africa, especially among those living in the rural areas, for their healthcare needs [1-9] Although large populations of rural dwellers in Africa rely on phytomedicine and other forms of CAM, most orthodox medical practitioners in the public health institutions hardly recognize and recommend them to their patients. Majority of those who prepare and offer phytomedicines to patients are usually not schooled in the science of the cultivation, harvesting, formulation, evaluation, storage and handling of the items that can assure safety [8-11]. Phytomedicine use is often criticized for lack of knowledge of the precise active

"Correspondence. E-mail: ikoni.ogaji@fulbrightmail.org Tel: +234-8023634482.

ISSN 0189-8442 (c) EY-NO 2021. Published by Faculty of Pharmaceutical Sciences, University of Jos, Nigeria. Under Creative Commons Attribution-Non-Commercial 4.0 International License. https://creativecommons.org/licenses/by-nc/4.0/ 
ingredients and accurate dosing of the preparations. Other concerns revolve around the secrecy of phytotherapy practitioners and the unscientific approaches and claims in the use of most of the herbal medicines [10-13]. Herbal medicine, whether used as dietary supplements or for other purposes, like other complementary and alternative medicines, is gaining patronage around the globe and this explains why the World Health Organization (WHO) encourages national governments to develop policies that would lead to their safe use [2]. Scientists have proposed that a systematic and scientific approach to phytotherapy practice has the potential to increase the confidence of the orthodox medical practitioners and the government on phytotherapy and other complementary and alternative medicines [14,15]. Pharmacy education, among others, covers the study of medicinal plants and their useful in healthcare delivery and pharmacists are the best professionals to explore and demonstrate the scientific basis for the use or otherwise of any phyto-therapeutic agent. Although over eighty percent $(80 \%)$ of Kenya populace depends on herbal medicines [3,5,9], phytomedicine is not currently integrated with the orthodox medicine in the government heath institutions. This situation has the potential of denying patients the benefit of a combined and synergistic healthcare system or choice of therapy. It is understood generally that career choices take place within the context of society and the economy and several career theories, such as Social Cognitive Career Theory and Social Learning, have explained the dynamics and drivers of career choices and development [16-19]. Consequently, events that take place in our lives may affect the choices available to us and even dictate our choices to a certain degree, and the choice of CAM as a career or profession is not an exception. Pharmacists can play crucial role in the integration of CAM into the orthodox healthcare delivery and their knowledge of, perception of, and attitude to
CAM, especially the phytomedicine, remain relevant [20-26]. There are studies that focus on the attitudes of practicing pharmacists and their customers towards the use of phytotherapeutic agents [10-13]. There is limited information in literature on the attitudes and perception of pharmacy students on the role of phytotherapeutic agents and other CAM. Undergraduate students are generally in their youthful age and are better suited to be agents of change.

Kenyatta University is one of the six universities in Kenya that offer pharmacy education that leads to the award of bachelor of pharmacy degree, the minimum qualification to practice pharmacy in the country [27]. Unlike other universities, Kenyatta University has a goal to train experts in complementary and alternative medicine, as reflected in the name it adopted from inception, 'Department of Pharmacy and Complementary and Alternative Pharmacy'. Although the current training still focuses on the training of the traditional pharmacists, extensive training in CAM is in the pipeline. The purpose of the study was to evaluate the perception, knowledge, attitude and the disposition of the pharmacy students to being trained as experts in CAM as a branch of pharmacy practice to take over from the traditional medicine practitioners that would be integrated into the national healthcare system.

\section{EXPERIMENTAL METHODS}

Study design. The study design was a descriptive cross-sectional study.

Study area. Department of Pharmacy and Complementary and Alternative Medicine, School of Medicine at Kenyatta University, Nairobi, Kenya was used for this study.

Study population. The study population is pharmacy students that are enrolled for conventional Bachelor of Pharmacy degree at a recognized university. 
Sample determination and sampling. Sample determination was based on the method of Krejcie and Morgan [28]. Sampling was random.

Data treatment and analysis. The cumulative responses to an item in the questionnaire were computed and the data analyzed using descriptive statistics. The target population was the pharmacy students in Africa where majority of the populace use phytomedicines and the sample was taken from the Department of Pharmacy and Complementary and Alternative Medicine, School of Medicine, Kenyatta University, Nairobi, Kenya. Pharmacy students at levels (2-5) but not level 1(not a professional level) participated in the study. Sample size for the study was determined using the method of Krejcie and Morgan [28] The study was carried out using a descriptive cross-sectional survey. Questionnaire was administered to the students to understand their knowledge of, perception, and attitudes towards CAM. The questions were directed at finding out if the students were opened to receiving a degree that limit them to the practice of CAM, reasons for choosing Kenyatta University with a departmental name emphasizing CAM, disposition to integrating CAM into the orthodox healthcare system. To eliminate internal invalidity and strengthen validity, the questionnaire was administered randomly to the willing students at the beginning of the term in the respective classes. The returned questionnaire was grouped according to the level of study, gender; and responses to items were pooled together. The data generated was analyzed using descriptive statistics to answer the research questions and conclusions were drawn on the basis of the data analyzed.

\section{RESULTS}

Demographics of pharmacy students in Kenyatta University. The total enrolment of pharmacy students in the university was 209 at the time of the survey out of which 119 (56.94
$\%)$ that was sampled responded and returned the questionnaire. The respondents comprised $65(54.60 \%)$ males and $54(45.40 \%)$ females. Based on level of study, 33, 45, 25 and 16 respondents respectively were from level 2, 3, 4 and 5 and no class had less than $53 \%$ of the nominal enrolment that returned the questionnaire. The respondents were aged 1830 years with the median age being 21 and the average age at $23 \pm 0.243$ years. The respondents comprised of both local students from all the geopolitical regions of the country, and foreign students from the East African sub region and the summary of the key responses are shown in Table 1 . Sixty (50.42\%) of the respondents first heard of CAM when they started processing their admission to Kenyatta University to read pharmacy and obtain a bachelor degree in pharmacy while 54 (45.38 $\%$ ) have heard of CAM before processing admission to Kenyatta University and the remaining $4 \%$ could not remember when they first heard about CAM. Generally, female students, irrespective of the level of study were more favorably disposed towards phytomedicine, as shown in Figure 1.

Knowledge of Complementary and Alternative Medicine by Pharmacy students. Majority of the respondents had basic knowledge of CAM and some components of CAM such as acupuncture, yoga, meditation, massage therapy and herbal medicine (not shown in Table 1). The level of knowledge on CAM was related to the study level of the pharmacy students. Those in higher classes had better knowledge of the components of CAM compared to those in the lower level. About $47.05 \%$ (56 respondents) asserted to having a good knowledge of herbal medicines while about $25 \%$ (30) do not feel they have a good knowledge of herbal medicines and the rest $28 \%$ were uncertain of their level of knowledge of this class of drugs. Twenty one ( $18 \%$ ) of the respondents have not heard or were uncertain if they have heard of complementary medicines or alternative 
medicine. Ninety-four (79 \%) respondents were excited to learn alternative and complementary medicine but $8.4 \%$ were not excited about complementary and alternative medicine as a profession for them. The survey, as shown in Figure 2, revealed that the level of study and the gender of respondents influenced the responses, with those in the higher levels less excited.

\section{Perception of pharmacy students to earning} a bachelor's degree in CAM. Regarding earning a degree in complementary and alternative medicine, fifty-nine $(49.58 \%)$ of the respondents were well disposed to earning a degree in CAM while $14(11.76 \%)$ were not and $36(30.25 \%)$ were uncertain. Irrespective of the level of study, the female students have higher disposition to studying and gaining knowledge in CAM than their male counterpart (Figure2) and the number of the respondents in favor of gaining knowledge on CAM decreased with increasing knowledge in pharmacy from the second to the fifth year. Figure 3 shows that about $65-75 \%$ of the respondents across the levels of study believed that CAM could be safe and efficacious. Female respondents, irrespective of the level of study, were more positive on the safety and efficacy of CAM than the male counterparts. The respondents were divided on whether or not the orthodox and CAM are equally effective, with 33.61, 27.73 and $38.66 \%$ respectively agreeing, disagreeing and not certain in their response to the question of whether or not orthodox and CAM are equally effective. With respect to preference of use of the two types of medicine, $36.97 \%$ prefer the CAM, 29.41\% prefer the orthodox and 25.21 $\%$ were uncertain of their preference. Interestingly, majority of the respondents $(78.15 \%)$ did not believe that CAM should be classified as dangerous and $8.4 \%$ respondents were uncertain with $16(13.45 \%)$ believing that CAM is dangerous. At the same time opinion was divided on whether or not orthodox medicines are generally safer than
CAM. Fifty-one (about $42.85 \%$ ) of the respondents disagreed and $38(31.93 \%)$ agreed that orthodox medicines are generally safer than phytomedicines and other complementary and alternative medicines. Eighty-six (72.27 $\%$ ) of the respondents do not believe that orthodox medicines are effective in all medical conditions. Fifty respondents $(42.01 \%)$ were uncertain whether CAM is as good as the orthodox medicine while 39 (32.77\%) and 30 $(25.20 \%)$ respectively agreed and disagreed that both are equally good. Eighty-nine (74.78 $\%$ ) of the respondents believed that CAM is used by both the poor and the rich in the society. On the other hand, seventy-two (60.5 $\%$ ) of the respondents did not feel they would recommend phytomedicines and other complementary medicines as first choice of therapy but a general note, one hundred and fourteen $(95.80 \%)$ of the respondents would recommend them. Whereas, $67(56.30 \%)$ of the respondents would be comfortable to offer CAM services $31(26.05 \%)$ would not while the remaining $21(17.65 \%)$ respondents were not sure if they would. Although all the respondents showed readiness to acquire knowledge on both orthodox and CAM, only $24(20.17 \%)$ of the respondents would not mind specializing in CAM.

Attitude and perception of pharmacy students towards practicing as CAM professionals. Ninety-four respondents (78.99 $\%)$ were excited to be trained in CAM, fifteen $(12.61 \%)$ were indifferent while $10(8.40 \%)$ were not excited Fifty-nine respondents were favorably disposed to earning a degree in CAM and to practice it. Twenty-four $(20.2 \%)$ of the respondents disliked the idea of obtaining a bachelor's degree in CAM and practicing as experts. Fifty (42. $02 \%$ ) of the respondents were not certain if CAM is better than the orthodox medicine practice while $42(35.29 \%)$ felt that CAM is better than the orthodox medicine. When the question on the comparison of CAM and orthodox was asked differently, the responses were also different. 
Asked whether orthodox and CAM are equally effective, the responses were 33 (27.73\%), 46 $(38.66 \%)$ and $40(33.61 \%)$ respectively disagreed, were uncertain and agreed.

Attitudes of pharmacy students towards being agents of change in the integration of CAM into the nation's healthcare delivery system. Ninety-six $(80.7 \%)$ respondents were in favor of integrating CAM into the national healthcare delivery system of Kenya while 11 $(9.24 \%)$ were not in favor of integration and the remaining $12(10.10 \%)$ respondents were undecided on this branch of knowledge concerned with medicinal drugs obtained from plants or other natural sources. Effect of level of study on the attitudes and perception of pharmacy students on the relevance of and possible introduction of CAM to the national healthcare system and pharmacy training curriculum is shown in Figure 4. Ninety-one (76.47 \%) of the respondents agreed that CAM is very relevant in modern healthcare and $86(72.27 \%)$ of the respondents would like CAM to be part of the undergraduate curricular in all schools of pharmacy in the country. With respect to its introduction to national healthcare, $96(80.60 \%)$ respondents would like CAM to be integrated the national healthcare system of Kenya.

Table 1: Some of the responses to the questionnaire on perception and attitude of pharmacy students of Kenyatta

\begin{tabular}{|c|c|c|c|c|c|c|}
\hline & Question & $\begin{array}{l}\text { Strongly } \\
\text { disagree }\end{array}$ & Disagree & uncertain & Agree & $\begin{array}{l}\text { Strongly } \\
\text { agree }\end{array}$ \\
\hline 1 & I have a good knowledge of herbal medicines & 7 & 23 & 33 & 49 & 7 \\
\hline 2 & I have heard of complementary medicine & 7 & 4 & 11 & 52 & 45 \\
\hline 3 & My parents use alternative medicines often & 17 & 32 & 34 & 30 & 6 \\
\hline 4 & $\begin{array}{l}\text { My parents prefer to use orthodox medicines to } \\
\text { complementary or alternative medicine }\end{array}$ & 20 & 19 & 31 & 39 & 10 \\
\hline 5 & $\begin{array}{l}\text { I am excited to learn alternative and complementary } \\
\text { medicine }\end{array}$ & 3 & 7 & 15 & 69 & 25 \\
\hline 6 & $\begin{array}{l}\text { I would like to earn a bachelor's degree in alternative } \\
\text { medicine }\end{array}$ & 15 & 9 & 36 & 28 & 31 \\
\hline 7 & $\begin{array}{l}\text { Alternative/complementary medicine is better than } \\
\text { orthodox medicine }\end{array}$ & 8 & 19 & 50 & 21 & 21 \\
\hline 8 & $\begin{array}{l}\text { Orthodox and alternative/complimentary medicines are } \\
\text { equally effective }\end{array}$ & 14 & 19 & 46 & 36 & 4 \\
\hline 9 & I prefer alternative medicine to orthodox medicine & 12 & 33 & 30 & 36 & 8 \\
\hline 10 & $\begin{array}{l}\text { I first heard of alternative medicine when I started } \\
\text { processing my admission to KU }\end{array}$ & 14 & 40 & 5 & 40 & 20 \\
\hline 11 & Alternative and complementary medicines are dangerous & 40 & 53 & 10 & 14 & 2 \\
\hline 12 & Orthodox medicine is effective in all conditions & 30 & 56 & 24 & 7 & 2 \\
\hline 13 & $\begin{array}{l}\text { Orthodox medicines are generally safer than alternative } \\
\text { and complementary medicines }\end{array}$ & 24 & 27 & 30 & 32 & 6 \\
\hline 14 & Alternative medicines are for the poor & 52 & 40 & 17 & 6 & 4 \\
\hline 15 & $\begin{array}{l}\text { I often advise people to go for alternative medicine as first } \\
\text { line treatment measures for their conditions }\end{array}$ & 21 & 51 & 24 & 18 & 5 \\
\hline 16 & $\begin{array}{l}\text { I will not advise people to use any form of alternative } \\
\text { medicine }\end{array}$ & 46 & 57 & 11 & 3 & 2 \\
\hline
\end{tabular}




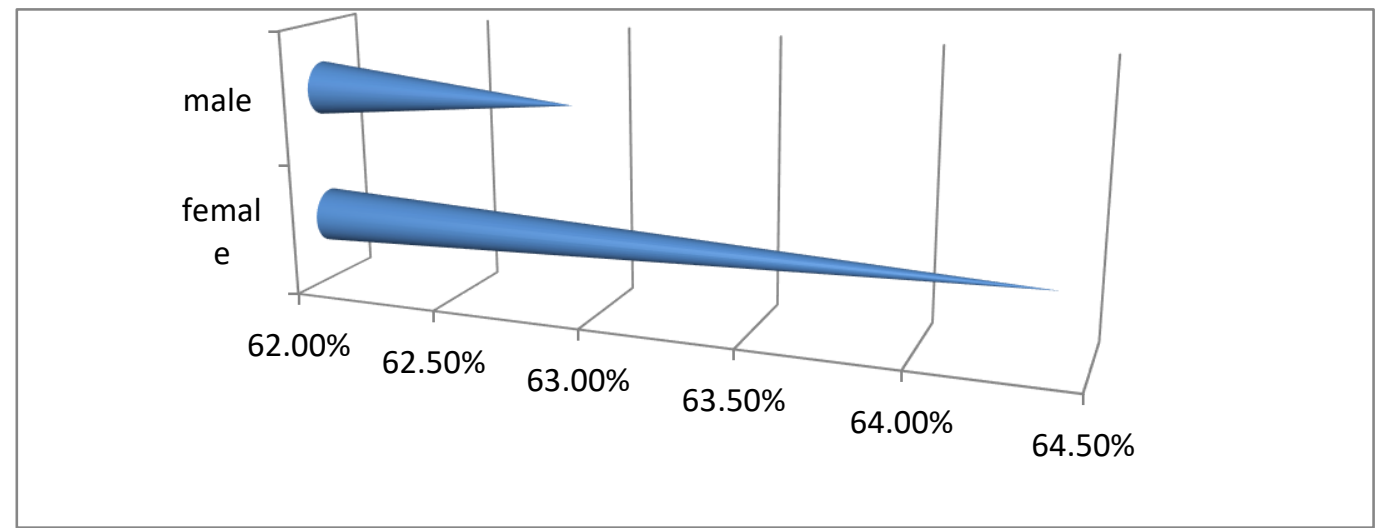

Figure 1: Effect of gender on the attitudes to and perceptions of pharmacy students complementary and alternative medicine

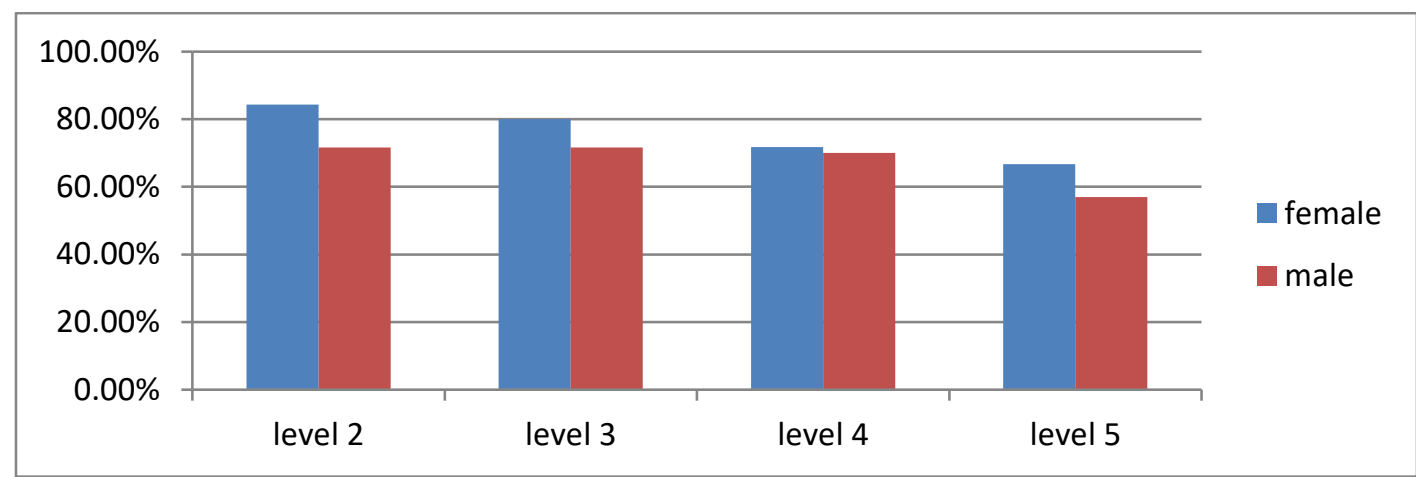

Figure 2: Effect of level of study on the attitudes and perception of pharmacy students towards gaining knowledge on CAM

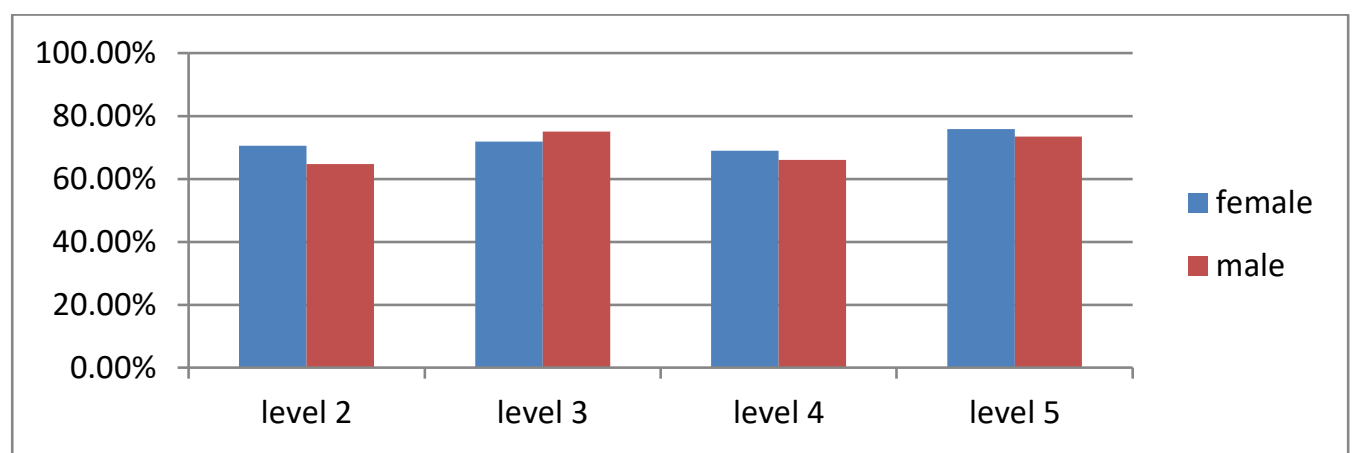

Figure 3: Effect of level of study on the attitudes and perception of pharmacy students on safety and efficacy of CAM

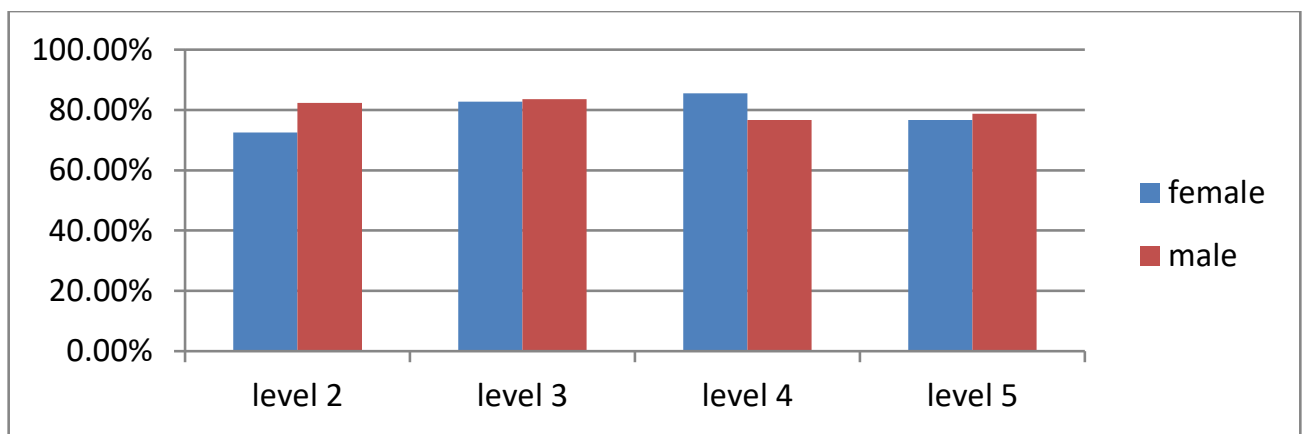

Figure 4: Effect of level of study on the attitudes and perceptions of pharmacy students on the relevance of and possible introduction of CAM to the national healthcare system and pharmacy training curriculum 


\section{DISCUSSION}

General. The demographic information about the participants in the study was both diagnostic and non-diagnostic. Whereas the total enrolment of the students in this program has nothing to do directly with the research question the ages and gender of the respondents may be of importance. The ages of the respondents fall in the category of the youth who are agents of change because of their predisposition to exploration and adventure. This indicates that the outcome of the study can give useful information of both sexes with regards to the research question. Studies have also shown that female gender reaction time to change is faster than those of the male counterpart [29]. This showed the sensitivity of the research approach to international convention and best practices and that the females were considered and that they had a say.

Basic knowledge of phytomedicine and other CAM. The two major factors which are considered important in human behavior are what people know (knowledge) and the views people take of things (attitudes). It is acknowledged that knowledge alone is not sufficient to change behavior but it is the most important and necessary first step to change in behavior [30]. This study has helped in understanding the level of knowledge of pharmacy students on CAM that is capable of providing information on the next levels of interventions. It is not unexpected to have about $50 \%$ of the students claiming that they have good knowledge of CAM in their opinion. This response is similar to the findings of other researchers [20-26]. This figure represented the number of respondents in the levels that have taken some courses in CAM. Level two pharmacy students do not take course in Pharmacognosy in which complementary and alternative medicine until their third year. The fact that the pharmacy students in this study had a fair knowledge of CAM is consistent with the fact that the teaching of CAM, especially Phytomedicine, is a component of pharmacy curriculum in pharmacy education in Kenya, although only Kenyatta University reflected CAM in the name of the programme. Pharmacy students would need to have the basic knowledge of CAM to participate in driving the change needed for the acceptance of CAM and subsequent integration into the national healthcare delivery system. Consequently, the actual knowledge of pharmacy students in response to factual questionnaire on some specific types of CAM was higher than their perception of knowledge on CAM.

It is hard to say in clear terms the gender factors that influenced the way the female and the male pharmacy students responded to the questionnaire and the implication for effective integration of Phytomedicine and other CAM into the national healthcare. It is, however, known that the enrolment of pharmacy students in Kenyatta University is almost evenly distributed between female and male [27]. Increased number of educated women means more empowerment and voice and improves the gender parity index. Studies have shown that women strengthen economy and increase the next generation's welfare and show more ethical behavior as well as do better in cooperate governance [29] Demographics also suggest that women live longer than their men counterpart and this would impact positively on the practice of CAM.

There are many variables to behavioral change models that are relevant to the development of strategies for the intended and desirable changes in behavior towards CAM by the pharmacy students and the healthcare professionals at large. These variables include fear, response efficacy, self-efficacy, benefits, subjective norms, attitudes, intentions, cue to actions and reactance. For each of these elements there are different strategies for behavioral change. Attitude is an individual's evaluation or beliefs about a recommended 
response and a measurement of the existing attitudes is a key strategy before any attempt to change them and therein lies the import of this study on the future custodians of phytomedicines. The respondents generally have a positive attitude to gaining knowledge on phytomedicine in particular and other CAM generally and would like to earn a bachelor's degree in CAM. The positive attitude shown by the majority of the respondents in this study to gaining more knowledge on CAM is consistent with the findings of other researchers that pharmacy students were eager to gain more knowledge on CAM [20-26, 30]. Related studies on practicing pharmacist and not pharmacy students revealed similar responses [31]. The turning point and the most distinctive approach in the present study was in the question of whether or not the students would be willing to accept a bachelor's degree that would license them on graduation to practice as CAM specialists instead of being custodian of orthodox medicine. Mwangi et al [32] have highlighted some constraints to integrating Phytomedicine into the mainstream orthodox medicine in the national health system of Kenya. Challenge on issues pertaining to safety, efficacy, quality, access and rational use of traditional herbal medicine and lack of healthy cooperation and communication between complementary medicine providers and medical practitioners can be addressed through training of professionals who have undergone requisite education and have the knowledge, skills and attitude to carry out the dedicated professional responsibilities regarding CAM. Self-efficacy and cues to action are very important variables in the behavior change. At the same time positive re-enforcement and planned intervention by the government can drive and sustain the change process. Formulation of national policy and establishment of legal framework are key areas that the government could act on without dragging of feet. Conditioning of the mind of the populace on the government efforts to assess evidence based, safe, pure and efficacious phytomedicine and other CAM is also very important. In general, appropriate application of the social cognitive, planned behavior and trans-theoretical models of change can be immense benefit. It is important that those in government and medical practitioners soften their stance and reticence handed over to them by the missionary founders who ardently oppose native practices and phytomedicine so as to facilitate the integration of phytomedicine and the enormous benefits to healthcare system [32]

Perception and disposition of pharmacy students to CAM. This study triangulated methods of obtaining information from the students by asking the same question in different ways with the hope of getting more precise responses. The study revealed that pharmacy students in universities can be motivated to be trained as experts in phytomedicines and other CAM. The generally favorable disposition of pharmacy students to practice as experts on phytomedicine can be ascribed to increasing knowledge on the potential efficacy and safety of phytomedicines when handled in line with best practices. This knowledge will continue to increase and set the stage for increasing role of phytomedicine in the healthcare delivery systems of many countries, particularly in the developing nations to make health accessible and affordable by the majority of the populace. Governments should not only formulate policies and frameworks but should purposefully put in place implementation strategies. The attitude of the general populace towards phytomedicine and other native practices need to change with increasing evidence- based practices of these forms of therapy. Curricular of schools of pharmacy should be refocused to be able to respond to the increasing need to integrate CAM to the national healthcare delivery system in Kenya and other African countries. 
Workforce for quality and safe practice and use of CAM in Kenya. As is characteristics of all cross-sectional studies the responses obtained and the conclusions drawn based on the data apply only to the situation as at the present and may change positively or negatively in the future. The factors that may lead to such changes may include the subjective norms and cue to action elements. Sherman [33] has demonstrated the influence of any sort of questioning-including questions about intentions, predictions of future behavior and measures of satisfactionon subsequent performance of that behavior. The response of pharmacy students is likely to be shaped similarly in the future [34-36] Whereas intrinsic motivation in eliciting a behavior cannot be predicted, it can be influenced by the external motivations. To sustain the expected response, a number of steps need to be taken by the government of Kenya and Kenyatta University [37, 38].

The commendable efforts of Women Fighting AIDS in Kenya (WOFAK) in working to sustain and promote various forms of traditional medicine and beneficial cultural practices throughout the country can be built on by the government [39]. Kenyatta University can borrow leaf from the WOFAK and similarly collaborate with the Kenya Forestry Research Institute or related establishment to grow, process, and conduct safety assessment and analysis of Phytomedicine intended to be incorporated or integrated into the national healthcare system. On the part of the national government, there are several models of integration of CAM into the mainstream healthcare system practice from which they can consider or borrow leaf.

Way forward in the integration and practice of CAM to national health care system of Kenya. Legislation, other professionals, perceived threat and reactance may work against the integration of CAM into the national healthcare delivery system in any of the four models. Medical professionals and religious persons need to see beyond the reticence of their founders who see phytomedicine and native practices as evil [32]. Deliberate efforts at encouraging specialization in CAM in the established pharmacy educational institutions would provide the necessary workforce for evidence -based CAM practice. National policies are the basis for defining the role of traditional and complementary/alternative medicine in national health care programs, ensuring that the necessary regulatory and legal mechanisms are created for promoting and maintaining good practice; assuring authenticity, safety and efficacy of traditional and complementary/alternative therapies; and providing equitable access to health care resources and information about those resources.

Conclusion. A study of the perception, knowledge and attitude of pharmacy students to Phytomedicine and other complementary medicine has been carried out. The students generally showed a good knowledge of complementary and alternative medicine especially those at higher levels of training with female students having slightly better knowledge than their male counterparts. The data collected demonstrated the difference in the opinions of Kenyatta university pharmacy students about safety and effectiveness of these treatments in relation to conventional medicine with many of the male students being uncertain and female students having a more positive attitude. The results showed the possibility of developing and training workforce that can contribute immensely to the smooth integration of evidence-based CAM into the national healthcare system if the enabling career and development environments are provided by the governments at various levels and other stakeholders.

Acknowledgements. The authors would like to acknowledge the contribution of the Department of Pharmacy and Complementary 
and Alternative Medicine that provided information on the enrollment of students and to all the research assistants.

\section{REFERENCES}

1.John, T, Kokwaro, J.O., Kimanani, K. E Herbal remedies of the Luo of Siaya District, Kenya: Establishing quantitative criteria for consensus. Economic Botany. 1990; 44; 367-81

2. World Health Organization. National policy on traditional medicine and regulation of herbal medicines Report of a WHO global survey, http://www.who.int/medicinedocs/en/d/Js7916e/, 2010 (Accessed 4thJune 2020)

3. Kigen, G., Some, F., Kibosia „J., Rono, H., Kiprop, E., Wannjohi, B., Kigen, P., Kipkores, W., Ethnomedicinal Plants Traditionally Used by the Keiyo Community in Elgeyo Marakwet County, Kenya. Journal of Biodiversity and Bioprospecting and Development. 2014;1;132. doi:10.4172/23760214.1000132

4. Kofi-Tsekpo, M.. Institutionalization of African traditional medicine in health care systems in Africa. African Journal of Health Sciences. 2004; i-ii.

5. Kemboi, D. Review of traditionally used medicinal plants by the Kipsigis community of Kenya. British Journal of Pharmaceutical Research. 2016;12; 1-6

6. Calixto, J.B. (2000) Efficacy, safety, quality control, marketing and regulatory guidelines for herbal medicines (phytotherapeutic agents). Brazilian Journal of Medicine and Biological Research. 2000; 33, 179-189

7. Robinson, M.M., Zhang, X. Traditional medicines global situation, issues and challenges. The world medicine situation ( $3^{\text {rd }}$ edn). WHO Geneva. 2011Ppp $1-14$

8. Abdullahi, A. Trends and challenges of traditional medicine in Africa. African Journal of Traditional and Complementary Medicine. 2011;8, 115-123

9. Fratkin, E. Traditional medicine and concept of healing among Samburu pastoralists of Kenya. Journal of Ethnobiology. 1996; 16,63-97

10. Naidu, S.; Wilkinson, J.M.; Simpson, M.D. Attitudes of Australian pharmacists toward complementary and alternative medicines. Annals of Pharmacotherapy. 2005;.39, 1456-1461.

11. Hogg, M., Vaughan, G. Social Psychology (4th edition). 2004. London: Prentice-Hall
12. Kwan, D., Boon, H.S., Hirschkorn, K., Welsh, S., Jurgens, T., Eccott, L, Heschuk, S., Griener, G.G, Cohen-Kohler, J.C. Exploring consumer and pharmacist views on the professional role of the pharmacist with respect to natural health products: A study of focus groups. BMC Complementary and Alternative Medicine.2008; 8, doi:10.1186/14726882-8-40.

13. Braun, L., Tiralongo, E., Wilkinson, J., Spitzer, O, Bailey, M., Poole, S., Dooley, M. Perceptions, use and attitudes of pharmacy customers on complementary medicines and pharmacy practice. BMC Complementary and Alternative Medicine.2010;10, doi:10.1186/1472-6882-10-38.

14. Ernest, E. The Risk-Benefit Profile of Commonly Used Herbal Therapies: Ginkgo, St. John's Wort, Ginseng, Echinacea, Saw Palmetto, and Kava. Annals of Internal Medicine. 2002; 136,42-53

15. Tesch, B. J._Herbs commonly used by women: an evidence-based review. American Journal of Obstetrics and Gynecology.2003; 188; S44-55.

16. Lent, R. W., and Brown, S. D. Integrating person and situation perspectives on work satisfaction: a social-cognitive view. Journal of Vocational Behavvior.2006; 69, 236-247. doi: 10.1016/j.jvb.2006.02.006

17. Lent, R. W., and Brown, S. D. Social cognitive model of career self-management: toward a unifying view of adaptive career behavior across the life span. Journal of Counselling Psycholology.2013; 60, 557-568. doi: 10.1037/a0033446

18. Lent, R. W., Brown, S. D., and Hackett, G. Toward a unifying social cognitive theory of career and academic interest, choice, and performance [Monograph]. Journal of Vocational Behavior. 1994;45, 79-122. doi: 10.1006/jvbe. 1994.1027

19. Lent, R. W., Brown, S. D., and Hackett, G. Contextual supports and barriers to career choice: a social cognitive analysis. Journal of Counselling Psychology.2000; 47, 36-49. doi: 10.1037/rep0000161

20. Noureldin, M., Murawski, M.M, Mason ,H.L, Plake, K.S. Student pharmacists' attitudes toward complementary and alternative medicine Journal of American Pharmaceutical Association.2013; 5; 618625. doi: 10.1331/JAPhA.2013.12212.

21. Tiralango, E., Wallis, M. Attitudes and perceptions of Australian pharmacy students towards Complementary and Alternative Medicine - a pilot 
study. Alternative Medicine. 2008;28, 8-12. doi: 10.1186/1472-6882-8-2.

22. Alkharfy, K.M. Community pharmacists' knowledge, attitude and practices towards herbal remedies in Riyadh, Saudi Arabia. East Mediterranean Health Journal. 2010;16, 988-993

23. Sweileh, W.M., Abu-Arrah, M.E., Abu-Taha, S.A., Sawaiha, F.A., Salah, A.O., Jamour M.R., Adawi, D. Dispensing practices, attitudes and knowledge of pharmacists towards herbal products in Palestine. Ibnosina Journal of Medicine and Basic Sciences. 2011; 5;123-130

24. Hanssen, B, Grimsgaard S, Launs $\varnothing$ L, Fønnebø V, Falkenberg T, Rasmussen NKR.

Use of Complementary and Alternative Medicine in the Scandinavian countries. Journal of Primary Healthcare. 2005; 57-62

25. Kandiah, J., Zimmerma, C. A pilot study to assess students' perceptions, familiarity, and knowledge in the use of complementary and alternative herbal supplements in health promotion. Alternative and Therapeutic Health Medicine. 2012; 18;28-33.

26. Berhanu, Z.K., 2016.Students' Perception Towards the use of Traditional Medicine for the Treatment of Mental Disorders: The Case of Arba Minch University. American Scientific Research Journal of Engineering Technological Sciences.2016; $6,32-52$

27. Ogaji, J.I, Okoyeukwu, P.C., Wanjiku, W.I., Osiro, E.A., Ogutu, D.A. Pattern of use of social media networking by Pharmacy students of Kenyatta university, Nairobi, Kenya. Computer in Human Behavior. 2017; 66; 211-216

28. Krejcie, R.V., Morgan, .B.W. Determining sample size for research activities. Educational Psycholological measurements. 1970; 30; 607-610

29. Franke, G. Differences in Ethical Perceptions of Business Practices: A Social Role Theory Perspective. Journal of Applied Psychology.1997; 82, 920-934

30. Chewning, J. The role of education in motivating positive behavior. https://www.corporatewellnessmagazine.com/article/ the-role-of-education-in-motivating-positivebehavior-change. Accessed $29^{\text {th }}$ August 2020

31. Atavwoda, A.T., Gabriel, A.A. Assessment of Pharmacists Knowledge, Attitude and Practices
Regarding Herbal Drug Information Services. Journal of Basic Clinical Pharmacy. 2012; 3, 317-322

32. Mwangi, J.W., Mungai, N.N., Thoithi, G.N., Kibwage, I.O.. Traditional herbal medicine in national healthcare in Kenya. The East Central African Journal of Pharmaceutical Science.2005; 8;22-26

33. Harington, J. http://www.africaresearchinstitute.org/newsite/blog/k enya-traditional-medicine-and-the-law/.( Accessed $12^{\text {th }}$ November 2016)

34. Sherman, S.J. On the self-erasing nature of errors of prediction. Journal of Personality and Social Psychology. 2013; 39; 211-21. doi:10.1037/00223514.39.2.211

35. Wilding, S., Conner, M., Sandberg, T., Prestwich, A., Lawton, R., Chantelle, W., et al. The question behavior effect: A theoretical and methodological review and meta-analysis. European Revolution and Social Psycholology.2016; 27;196230, DOI: 10.1080/10463283.2016.1245940

36. Sprott ,D. E., Smith, R. J., Spangenberg E R, Freson T S. Specificity of

prediction requests: Evidence for the differential effects of self-prophecy on commitment to a health assessment. Journal of Applied Social Psychology. 2004;34,1176-90. doi:10.1111/j.1559-1816. 2004.tb02002.x

37. Sprott, D. E., Spangenberg, E. R., Block, L.G., Fitzsimons, G.J., Morwitz, V.G., Williams, P. The question-behavior effect: What we know and where we go from here. Social Influence. 2006; 1; 128-37. doi:10.1080/1553451060068540921-9010.88.3.423

38. Lambert, J., Leonard, K., Mungai, G., OmindeOgaja, E., Gatheru, G., Mirangi, T.,et al.he contribution of traditional herbal medicine practitioners to Kenya healthcare delivery. Health, Nutrition and Population (HNP) Discussion Paper. The International Bank for Reconstruction and Development/ World Bank 1818 H Street, NW, 2011; Washington DC

39. Simkin, D.R., Popper, C.W. Overview of integrative medicine in child and adolescent psychiatry. Child and Adolescent Psychiatric Clinic in North America. 2013; 22;375-80, v. doi: 10.1016/j.chc.2013.05.002

40. WOFAK . https://www.wofak.org/about-us/ (Accessed $4^{\text {th }}$ Jun2020) 